\title{
Texto, enunciação e as práticas (políticas) de ensino de línguas: contribuições da Semântica do Acontecimento para pensar os sentidos no ensino da língua portuguesa
}

\author{
Text, enunciation and the practices (policies) of language teaching: \\ contributions from the Semantics of the Event to reflect about the senses in \\ teaching Portuguese
}

\author{
André Stefferson Martins Stahlhauer ${ }^{1}$ \\ Instituto de Romanística da Friedrich Schiller Universität Jena, Jena-Thüringen, Alemanha \\ Claudia Freitas Reis ${ }^{2}$ \\ Instituto Federal de São Paulo, Araraquara, Brasil
}

\begin{abstract}
- RESUMO: A proposta desse artigo é apresentar uma discussão e um encaminhamento sobre o modo como as questões teóricas propostas pela Semântica do Acontecimento nos permitem refletir, por um lado, sobre a própria importância da Semântica, como um campo do saber e da Linguística, e de outro, para o ensino de português. Considerando a forma como as noções de língua, linguagem, sentido, texto, argumentação, político e espaço de enunciação permeiam esta teoria, ou seja, situando nossa compreensão sobre como se dá a constituição dos sentidos da(s) e na(s) língua(s), propomos uma reflexão que trata do lugar de uma semântica em sala de aula e do modo como operar com a língua/linguagem dentro do ensino de português em diferentes modalidades, o português como língua oficial do Brasil e o português como língua estrangeira.
\end{abstract}

- PALAVRAS-CHAVE: Semântica, Linguagem, Sentido, Ensino, Português.

- ABSTRACT: This paper aims to present a discussion around the theoretical issues proposed by the Semantics of Event theory, which allow us to reflect on the importance of Semantics as a field of the Scientific Knowledge and a part of Linguistics, as well to the teaching of Portuguese. Considering how the notions of language, sense, text, argumentation, politics, and space of enunciation permeate this theory, that is also situating our understanding about how the constitution of the senses of and in the language(s) takes place, we propose a reflection that focusses on the place of semantics in the classroom and the way it can operate with the language within the teaching of Portuguese, the official language of Brazil, in different modalities, Portuguese for Brazilians in regular education, and Portuguese as a foreign language.

- KEYWORDS: Semantics, Language, Senses, Teaching, Portuguese.

[...], pois só há línguas porque há falantes e só há falantes porque há linguas. $[\ldots]$

Esta relação entre falantes e línguas interessa enquanto um espaço regulado $e$ de disputas pela palavra e pelas línguas, enquanto espaço político, portanto. A língua é dividida no sentido de que ela é necessariamente atravessada pelo político: ela é normativamente dividida e é também a

\footnotetext{
${ }^{1}$ Doutor em Linguística pela UFSCAR. Docente do Instituto de Romanística da Friedrich Schiller Universität Jena, Jena-Thüringen, Alemanha andrestahl.revisor@gmail.com, andre.stahlhauer@unijena.de.

2 Doutora em Linguística pela UNICAMP. Docente do Instituto Federal de São Paulo, Campus Araraquara, Araraquara- São Paulo-Brasil clauin@gmail.com, claudia.reis@ifsp.edu.br
} 
condição para se afirmar o pertencimento dos não incluídos, a igualdade dos desigualmente divididos.

Eduardo Guimarães, em Semântica do Acontecimento.

\section{Apresentação}

Diante da necessidade de escrever um texto teórico-reflexivo sobre nossas atuações acadêmico-profissionais, sentimos a necessidade de relatar, também, nosso percurso enquanto pesquisadores, professores e amigos. Ao escrever esse trabalho sentimos, ainda, a necessidade de manifestar a alegria de ter feito esse percurso sempre em conjunto, em diálogo. Sempre fomos leitores um do outro. Esse texto é o primeiro de muitos que virão de uma parceria de mais de dez anos que vem desde os tempos de nossa formação inicial em Letras, quando desenvolvemos nossos trabalhos na UFSCar com a Soila ${ }^{3}$, quem nos apresentou a teoria da Semântica Histórica da Enunciação. Foi através de seus livros, de seus textos e dos artigos de Eduardo Guimarães, e de outros eminentes autores, que líamos nas reuniões de grupo de pesquisa da Unidade de Estudos Históricos, Políticos e Sociais da Linguagem (UEHPOSOL), que conhecemos a teoria que deu rumo e eira aos nossos trabalhos acadêmico-profissionais. A teoria da Semântica do Acontecimento permeia nossas reflexões, nossas observações, nossas análises linguísticas e nosso olhar sobre a língua/linguagem. Essa teoria também que embasa nosso trabalho como professores de português.

\section{O semântico e a semântica}

Em tempos em que se evidenciam os ataques aos saberes acadêmicos em suas práticas reflexivas, inclusivas, que constituem o jogo democrático na sociedade brasileira, faz-se necessário discutir, ao menos que brevemente, em função da complexidade do tema, sobre a importância dos estudos em semântica, enquanto disciplina da grande área institucional acadêmico-científica da Linguística e do campo das Letras que também produz efeitos em práticas de ensino de línguas, notadamente, tomando como referência nossas práticas em sala de aula, no ensino de português, no Brasil, para brasileiros e português do Brasil, no exterior, para estrangeiros. Nesse sentido, é fundamental que se aborde o semântico, como ponto nodal da constituição desse campo do saber e do conhecimento ${ }^{4}$, como objeto científico que tem na significação e no sentido das palavras e expressões linguísticas o seu objeto teóricometodológico e enquanto elemento constitutivo de todas e quaisquer relações de linguagem. Para conduzir a discussão proposta, apresentaremos nossas reflexões a partir de uma semântica de base histórico-enunciativa, apontando de que forma esse lugar teórico produz conhecimento científico sobre a língua e para a prática do professor de língua/linguagem, no modo como ela já é, por sua natureza, uma prática simbólica e que se constitui materialmente de uma história e de uma política, ou seja, de uma tomada de

\footnotetext{
3 A Profa. Dra Soeli Maria Schreiber da Silva, a quem carinhosamente chamamos de Soila, é professora titular no Departamento de Letras da Universidade Federal de São Carlos.

4 Muitas questões apresentadas no artigo foram expostas no III Encontro de Professores de Línguas do Litoral Norte - EPLIN 2019, realizado no IFSP - Câmpus Caraguatatuba, no dia 14 de setembro de 2019. $\mathrm{Na}$ mesa redonda "O ensino de línguas sob diferentes perspectivas: teoria e prática", que abriu o evento, Claudia Reis apresentou o trabalho "Texto, enunciação e as práticas de ensino em língua materna: a semântica nas aulas de língua portuguesa”.
} 
posição, e de uma decisão, desse sujeito-falante, que é o professor ${ }^{5}$. Parece óbvio, mas é necessário desenvolver a questão da natureza e do funcionamento da língua enquanto objeto científico e enquanto objeto do saber em práticas de ensino. Consideramos, assim, que o ensino de línguas deve extrapolar o tratamento da(s) língua(s) como meros instrumentos de comunicação, mas como o próprio modo de inserção dos sujeitosfalantes no mundo, em sociedades constituídas, significadas, pelo simbólico.

Queremos, com isso, demonstrar o caráter científico, teórico-metodológico empreendido por uma Semântica da Enunciação ${ }^{6}$, a Semântica do Acontecimento, a fím de utilizar uma designação teórica mais pontual, e mostrar como essa frente de pesquisa, que constitui uma área acadêmica no interior de uma prática científica do campo da Linguística, é necessária e pode ser retomada, recortada, interpretada como subsídio para as observações, reflexões e análises possíveis em uma sala de aula cujo foco é o ensino de uma língua. Para tanto, é necessário tomar "ensino de língua" como enunciado de sentido amplo, que comumente se apresenta como aprender e ensinar um instrumento de comunicação, de interação que estabelece laços sociais ou que significa como a inserção do falante-aprendente em uma nova ou outra cultura, no caso de ensino para estrangeiros. Sobre essa forma de pensar o ensino de português, é preciso ressaltar que consideramos "o estrangeiro" como um modo de alocutar o outro, como uma representação de um falante de outra nação, no dizer, na linguagem, ou seja, que, assim como o falante, esse modo de representação na língua é uma figura da enunciação, constituída no modo como a língua está dividida pelo falante.

Vamos considerar esta prática como modo de distribuir e dividir uma língua instrumentalizada no ensino, prática que configura, em representações, imaginários e faz circular discursos sobre as línguas e seus falantes. Dessa forma, é necessário que se considere, também, no interior desse arcabouço, a política e o político ${ }^{7}$ na constituição dos sentidos, que, na nossa perspectiva, são peças fundamentais que determinam qualquer processo linguístico, seja ele de aprendizagem ou de outra ordem, pois todo o processo de ensino, podemos afirmar, e todo processo de linguagem é pautado na produção de sentidos. O sentido é o que faz falar, dizer e significar, pois ele sempre está ali de modo a se projetar, a se recolocar como o mesmo ou como novo, como outro diferente de si.

Ao mostrar as contribuições da Semântica do Acontecimento instauramos, necessariamente, uma divisão dentro do próprio campo de saber denominado Semântica. Afinal, o que significa semântica dentro dos estudos linguísticos? Nosso objetivo nesse artigo não é realizar um trabalho sobre a história da semântica propriamente ou mesmo sobre história das ideias, mas é importante considerar que um posicionamento teórico nos leva a determinada prática docente e isso será um ponto fulcral em nossa discussão.

\footnotetext{
${ }^{5}$ A questão é justamente mostrar que é sempre uma tomada de decisão, que pode ser mais ou menos consciente. Faz-se necessário pontuar, contudo, que não voltaremos às questões sobre uma hermenêutica do sujeito nesta ocasião.

${ }^{6}$ De acordo com Ferreira (2012) “O nome Semântica da enunciação continuará presente ao longo das pesquisas de Eduardo Guimarães, até desembocar na semântica histórica da enunciação e na semântica do acontecimento. Nos estudos do autor, o diálogo estabelecido com a análise de discurso e com outras teorias no espaço científico brasileiro, foi produzindo uma necessidade de considerar outras questões para a sua semântica, como a história e a ideologia".

${ }^{7}$ Tomamos essas duas noções a partir das propostas de Guimarães (2002) e Orlandi (2008).
} 
Segundo Rodolfo Ilari, no prefácio que faz ao livro "Semântica, semânticas: uma introdução", ${ }^{\text {, nos diz: }}$

O que faz a singularidade das teorias não é, como se pensa às vezes, o objeto de que tratam; são antes seus pressupostos (ou seja, as crenças que a teoria assume sem explicitá-las) e os métodos usados para chegar aos objetivos visados. Outro fator de diferenciação é o peso que as teorias dão à especulação sobre questão de princípios, em oposição à quantidade de dados empíricos que julgam necessários reunir para que a investigação empírica possa começar. [...] embora as linhas de pesquisa nele consideradas sejam unânimes em declarar-se comprometidas com o esclarecimento de sentido da língua natural ${ }^{9}$, cada uma delas constrói uma noção de sentido própria, que só se justifica e ganha foros de realidade quando inserida num contexto teórico muito particular." (ILARI, 2013, apud FERRAREZI JUNIOR e BASSO, 2013, p.10)

Assim não podemos prescindir da singularidade, e, por isso, de uma identidade, das teorias; tampouco nossa questão é dizer qual deve ou não estar presente em sala de aula. Parece-nos que o movimento é entender que a ciência é atravessada pelo político, sendo esse compreendido como divisão, contradição, litígio e essa é exatamente a tônica da produção do conhecimento e das práticas investigativas, algo profícuo para o próprio crescimento da produção científica.

Nossas reflexões sobre as questões linguísticas estão pautadas, sobretudo, nos estudos propostos por Eduardo Guimarães, na linha de Semântica na linha da Semântica Histórica da Enunciação e da Semântica do Acontecimento ${ }^{10}$. Isto é, em nosso percurso acadêmico-profissional, desenvolvemos dissertações e teses com esse aparato teóricometodológico. E essa teoria, seus pressupostos, suas referências e inter-relações com a Análise do Discurso e outros campos do saber como a filosofia política e a história, determinam nosso modo de atuar como professores de língua.

Segundo Eduardo Guimarães (2018), é insuficiente dizer que a semântica é a disciplina que estuda a significação já que isso implica em especificar o que se entende por significação. Assim, nosso entendimento corrobora a proposta do autor de que:

[...] a semântica é uma ciência que tem por objetivo o estudo da significação. E a significação nós a consideramos como sentido, ou seja, como produzida pela enunciação, em outras palavras, pelo funcionamento das línguas num espaço de enunciação (GUIMARÃES, 2018, p.22)

Podemos pontuar que a produção de sentido, nessa perspectiva, se dá a cada enunciação, em seu acontecimento. Ou seja, os sentidos não são estáticos, não são homogêneos, pelo contrário, são instáveis, opacos e se produzem historicamente.

E a semântica, enquanto uma semântica da enunciação, é a disciplina que analisa os sentidos dos enunciados enquanto enunciados que integram textos nos acontecimentos que a produzem. (GUIMARÃES, 2018, p.22)

\footnotetext{
${ }^{8}$ No livro, os autores Ferrarezi Junior e Basso buscam trazer as divergências e convergências teóricas dentro da designação de semântica, e apresentam um quadro com algumas das diversas linhas teóricas que são nomeadas de Semântica.

9 Sobre as expressões língua natural e língua "artificial", gostaríamos de ressaltar que de acordo com nossa perspectiva teórica, tomamos a língua pelo histórico. Isto é, não há língua que seja natural, pois mesmo cientificamente, a língua já é um objeto científico e, por isso, histórico.

${ }^{10}$ Com a publicação, em 2002, do livro "Semântica do Acontecimento", Eduardo Guimarães desenvolve uma teoria semântica que articula as questões enunciativas no diálogo com as propostas discursivas da Análise do Discurso e a Filosofia política.
} 
Assim, essa forma de pensar os estudos semânticos nos coloca diante da questão do texto. Ou seja, pensar no sentido implica pensar no texto. É importante dizer que a questão da palavra e de seu sentido se mantem, no entanto, entendemos que esse estudo precisa, necessariamente, estar atrelado à relação palavra/enunciado/texto, relação essa que chamamos integrativa. Nessa perspectiva, deslocamos os estudos semânticos do caráter puramente lexical, que é como normalmente a semântica é compreendida, e apresentamos um olhar sobre o texto, ou seja, tomamos o estudo do sentido da palavra que é significada em sua relação com um texto. O texto enquanto uma materialidade significante e não uma simples correlação de elementos. Para Guimarães (2011):

[...] considerar que a questão central, para o ensino da compreensão e produção de texto, não é a da correlação linguística, [...] não quer dizer que os aspectos conhecidos como gramaticais não tenham interesse. Ou seja, o principal a se observar no texto não é se ele é correto, segundo um padrão linguístico normatizado. Trata-se de considerar como ele faz sentido. [...] (GUIMARÃES, 2011, p. 127)

Uma vez que consideramos que os sentidos das expressões linguísticas se constituem historicamente em regularidades, nos contrapomos a uma noção que considera a sua imanência, ou valor estrutural. Sendo assim, os sentidos apresentados pelo dicionário, em definições que, por suas vezes, se apresentam como uma normatividade, devem ser trazidos à discussão e considerados também sob outras formas de construção, em regularidades linguísticas, nos textos que ocorrem. Esse modo de tratamento do sentido é importante para se propor, ainda, um modo de se observar como se dá a escrita e a escolha dos textos para compor os materiais de ensino. Assim, consideramos que o que os materiais didáticos apresentam, em geral, como antonímia, sinonímia, hiperonímia, conceitos caros às semânticas formal e lexical em suas diversas vertentes, são processos produzidos pelo modo como um locutor se inscreve nos efeitos de sentidos e que estão determinados pelas relações textuais. De qualquer forma, a Semântica não poderia ser reduzida somente a essas relações, já que, como estamos propondo, ela é algo mais complexo, se tomada na relação com uma teoria linguística, ou ainda, em se considerado o funcionamento histórico da linguagem, ela é muito mais dinâmica, rica e heterogênea nas formas de produzir significação.

Com as questões apresentadas queremos trazer à tona o fato de que a semântica pode ser tomada em uma relação que extrapole a ocorrência léxico-gramatical da palavra. Dentro do que apresentamos, o trabalho com o texto passa a ser uma questão própria e imprescindível para a disciplina o que constitui mais um ponto que sustenta nosso posicionamento de que o semântico recobre a prática docente como um todo. Nesse sentido, podemos dizer que todas as disciplinas, na medida em que estão relacionadas ao trabalho com o texto, um trabalho de interpretação que é iminentemente de leitura e autoria ${ }^{11}$, estão mobilizando a produção de sentido. Dito de outro modo, as questões de linguagem não podem ser consideradas apenas nas aulas de língua ou da área de linguagens. É necessário que o processo de compreensão e produção de sentidos seja construído também no processo de ensino-aprendizagem de outras áreas e balizados por conceitos e embasados em teorias que o considerem para além de uma relação forma-conteúdo, em que o texto é o resultado ou produto que transmite uma ideia, um pensamento, uma pesquisa, quando no interior da prática de ensino, no modo como o material de ensino é tomado, ele é o próprio modo de construção do conhecimento. É nesse sentido que o trabalho com o texto deve extrapolar as relações formais, inclusive

\footnotetext{
${ }^{11}$ No modo como Guimarães (2011) mobiliza essas noções.
} 
as de delimitação das unidades linguísticas de palavra, frase, oração, período, enunciado, texto, discurso, etc., já tão didatizadas pela escola e pelos materiais.

Trabalharemos, na sequência, com conceitos teóricos importantes mobilizados pela Semântica do Acontecimento que produzem, segundo nossa proposta, deslocamentos fundamentais que desnaturalizam a relação do professor com os instrumentos linguísticos (gramáticas, dicionários e também os materiais de ensino) e que contribuem para uma prática de ensino que corrobora as questões sobre a produção de sentido expostas no item anterior. Considerando a riqueza de articulações possíveis entre a teoria e prática de ensino, trazemos os conceitos de argumentação, espaço de enunciação, língua e suas divisões.

\section{Texto, argumentação e ensino}

Para tratar das questões dos sentidos nos textos, é fundamental que se aborde a argumentação na relação entre a teoria da Argumentação na língua, formulada por Oswald Ducrot, a Semântica Argumentativa, e a Semântica do Acontecimento, a fim de tecer as devidas correlações teóricas entre os sentidos das palavras no enunciado e seus modos de integração em um texto.

A nossa questão, ao mobilizarmos o conceito de argumentação, tem a ver, justamente, com o modo como aparece na teoria da Semântica do Acontecimento, tendo sido mobilizado em diversos trabalhos de Eduardo Guimarães, que inter-relaciona os conceitos da Semântica Argumentativa, de base enunciativa, em Oswald Ducrot, e os trabalhos em Análise de Discurso.

A discussão teórica que aqui propomos se caracteriza pela relação entre a língua e seu exterior (a história). Como já proposto, em Stahlhauer (2010), de acordo com as posições com as quais trabalhamos, nosso interesse na linguagem é a significação e o sentido. Segundo Ducrot (1999), texto em que discute a teoria dos topoi na língua, o sentido de uma expressão se constrói no enunciado. $O$ autor rediscute a questão da noção de valor do signo, transpondo-a ao enunciado, no texto em que o enunciado é produzido. Os enunciados são, assim, unidades constitutivas de textos que se fazem como encadeamentos discursivos, segundo as posições desse autor. Nesse momento, a teoria da argumentação na língua (ANL) discute suas análises da argumentação em "atos argumentativos". A teoria se preocupava em estabelecer o que era linguístico dentro de uma situação retórica. A argumentação ainda era observada em uma esfera que, ao admitir o ato de argumentar como situação comunicativa, mesmo não admitindo o caráter informativo da língua, tinha um caráter retórico. Para ele, nesse momento, o semanticista deveria descrever o que, em uma argumentação, no sentido retórico, teria o valor linguístico. Em outro momento, em que o autor discutia a noção de topos na teoria da ANL, a teoria da argumentação na língua, o funcionamento da língua tinha suas bases numa esfera psicossocial da linguagem, na medida em que "as garantias" ou lugares comuns argumentativos (a teoria dos "topoi”" na língua) é o que produziam a significação e, por isso, direcionavam os sentidos para o que está fora da língua (relação entre língua, sujeito e mundo). É a partir dessa concepção que estabelecemos nossa maneira de pensar a argumentação. No entanto, consideramo-la de outro modo, ao colocá-la em relação ao sentido na língua e à historicidade que o constitui. Deslocamos nossa posição da de Ducrot, considerando-a como um elemento da textualidade, como efeito de sentido e não como uma condição linguística. Em os Limites do Sentido, Guimarães (2010), esta ancoragem teórica desenvolve-se quando o autor expõe suas discussões sobre argumentação no funcionamento histórico dos sentidos pelo interdiscurso. 
A discussão sobre argumentação aqui apenas pontuada ${ }^{12}$ quer mostrar que a contribuição dos estudos argumentativos para a Semântica do Acontecimento é, necessariamente, o modo como o sentido de uma palavra ou das expressões significam em um texto. Isto é, o modo como há um movimento de sentidos que independe da vontade do sujeito e que na realidade é o sentido que organiza a própria significação no texto. Obviamente o trabalho do semanticista, do acadêmico, é diverso ao do professor de línguas em sala, mas inegavelmente, o modo de olhar para a argumentação, quando se desloca da posição da retórica ou de uma visão estruturalista, é que a teoria da argumentação constitui uma gama teórica importantíssima para se pensar o princípio de produção de sentidos. Assim, relacionar teoricamente a noção de argumentação, como em Guimarães, com o funcionamento da língua é deslocar a visão de que o linguístico é estrutural. Nesse sentido, retomamos outra citação:

\begin{abstract}
Argumentar é, mais que estabelecer uma conclusão, silenciar outros percursos da significação textual. E este efeito do silêncio constitutivo, esta política do silêncio tem na língua marcas específicas que se põem em funcionamento na enunciação, ou seja, movimentadas pelo interdiscurso. Há algo da política do silencio que se abriga no simbólico da linguagem: na língua. (GUIMARÃES, 2002, p 82).
\end{abstract}

É fundamental, portanto, que se considere a argumentação para além da esfera psicossocial de utilização da língua, como mero instrumento das capacidades cognitivas e psíquicas do sujeito, mas como indissociável do funcionamento da própria linguagem em seu funcionamento histórico, ou seja, é considerar o texto e a textualidade em um duplo movimento de constituição e circulação de sentidos. A nossa questão é dar à língua/linguagem o seu devido estatuto na formação de autores e de leitores, no trabalho com as expressões linguísticas, na significação da contiguidade nos textos, sua consistência e textualidade, o que nos permite observar o texto como unidade sóciohistórica de significação. É fazer movimentar o sentido de palavras que funcionam não só, mas também, como operações de sentido para levar os alunos-falantes-leitoresautores, expostos a uma instância de aprendizagem, a compreender o funcionamento das materialidades linguísticas como formas de uma história e como um modo de fazer circular uma prática de instrumentalização da língua que marca formas de uso a serem reproduzidas, repetidas ou deslocadas, movimento que caracteriza repetições, rupturas ou resistências com sentidos que se impõem sobre os falantes.

\title{
3. As divisões da língua e o espaço de enunciação: semântica e política de línguas
}

Outra questão importante é a divisão da língua. Isso porque não há como enunciar "ensino de português" sem problematizar "qual português" e o que significa trabalhar com ensino de português para brasileiros ou estrangeiros. Ou seja, dizer que ensinamos língua já nos coloca diante de várias designações que precisam ser discutidas e explicitadas, sobretudo por aqueles que se propõe o desafio. Com essas afirmações, queremos dizer que o professor de língua precisa de um posicionamento sobre o que é uma língua.

É nesse ponto que se imbricam os trabalhos de Guimarães em semântica e o que ele considera como político e uma política de línguas. Um dos encaminhamentos que

\footnotetext{
${ }^{12}$ Essas questões também são desenvolvidas em STAHLHAUER (2010)
} 
podemos fazer, quando consideramos a semântica e o semântico no ensino de línguas ${ }^{13}$, é que devemos considerar esses jogos de designações que subjazem toda e qualquer fala sobre a língua. Nesse sentido, é preciso considerar sempre o movimento intersubjetivo não apenas no sentido que Benveniste (1988) dá à intersubjetividade, mas também no sentido de que não há funcionamento da língua fora dessa relação entre falantes, entre identidades, que tomamos como locutores. É aí que funciona o simbólico no modo de fazer significar essas designações de língua, ou seja, ensinar português é extrapolar os limites de uma língua instrumentalizada pelas gramáticas e dicionários, mas transpor para o material de ensino que se adota, escreve ou compila a perspectiva de que uma língua é línguas, pois é, sobretudo, relação entre falantes, sujeitos em disputa, em consensos ou dissensos. Nessa relação é preciso mostrar nos recortes que se fazem sobre o ensino, seja em classes gramaticais, em sintaxe, em morfologia, em expressões, em sequências de textos, os sentidos que se produzem nesses materiais, para muito além de repetir a língua ali instrumentalizada. Comecemos, então, a mostrar o que é, para nós, nesse espaço de ensino, o conceito de espaços de enunciação. Para Guimarães,

(...) são espaços de funcionamento de línguas, que se dividem, redividem, se misturam, desfazem, transformam por uma disputa incessante. São espaços "habitados" por falantes, ou seja, por sujeitos divididos por seus direitos ao dizer e aos modos de dizer. São espaços constituídos pela equivocidade própria do acontecimento: da deontologia que organiza e distribui papeis, e do conflito, indissociado desta deontogia, que redivide o sensível, os papeis sociais. O espaço de enunciação é um espaço político (...). (GUIMARÃES,2002, p.13)

O espaço de enunciação tem a ver com o enunciável e o político, com o agenciamento enunciativo: aquilo que se diz, o modo como se diz e quem diz em um espaço afetado por uma política, Stahlhauer (2019). Dessa maneira quando falamos sobre ensino de português, falamos de um espaço de distribuição e divisão de línguas a falantes. Nesse movimento, delineia-se um espaço em que as injunções à aprendizagem de formas, expressões, nomes de autores de literatura, estilos, etc., se formulam em uma língua: o português. Nessa maneira de atuar, há um movimento de apagamento da pluralidade e da multiplicidade de sentidos que aí funcionam. Estamos querendo dizer com isso que é necessário considerar no trabalho com as línguas os seus modos de divisão, que as fazem funcionar. Em Guimarães (2006), temos que:

\footnotetext{
Língua materna: é a língua cujos falantes a praticam pelo fato de a sociedade em que se nasce a praticar; nesta medida ela é, em geral, a língua que se representa como (que se apresenta como sendo) primeira para seus falantes.

Língua alheia: é toda língua que não se dá como materna para os falantes em um espaço de enunciação.

Língua franca: é aquela que e praticada por grupos de falantes de línguas maternas diferentes, e que são falantes desta língua para o intercurso comum. Língua nacional: é a língua de um povo, enquanto língua que o caracteriza, que dá a seus falantes uma relação de pertencimento a este povo.

Língua oficial: é a língua de um Estado, aquela que é obrigatória nas ações do estado, nos seus atos legais.
}

\footnotetext{
${ }^{13} \mathrm{O}$ que apresentamos como divisões de línguas é tratado, considerados os distanciamentos teóricos, dentro da Sociolinguística e suas ramificações como as variantes linguísticas. Trazemos isso pois essa perspectiva teórica é bastante popularizada na escola e, em geral, é a adotada quando o assunto é produzir uma reflexão sobre o tema que abordamos. Nossa crítica a essa forma didatizada apresentada nos livros didáticos é que ela, ao classificar as diferenças, acaba limitando e simplificando a complexidade do funcionamento linguístico. Nesse sentido, ressaltamos, mais uma vez, a importância da formação do professor para questionar e problematizar os temas/conteúdos dos livros didáticos.
} 
Língua estrangeira: é a língua cujos falantes são o povo de uma Nação e Estado diferente daquele dos falantes considerados como referência. (GUIMARÃES,2006, p. 14)

A nossa questão ao apresentar essas definições sobre divisões nos modos de distribuição das línguas é justamente pela reflexão que se pode fazer sobre o que significa ensinar português, português do Brasil ou a língua brasileira ${ }^{14}$. É mostrar que o português, língua oficial e nacional do e no Brasil, tem funcionamentos históricos e que a colonização, e seus discursos, fez com que essa língua se impusesse em relação desigual e hierárquica com as línguas, lê-se falantes, que aqui eram e que viriam a ser faladas no decorrer da história do Brasil e dos brasileiros. É, nesse sentido, considerar que o português não foi e não é a única língua do Brasil, falada por brasileiros e que sua historicidade, determinada pela colonização, a escravidão, as imigrações e outros processos históricos, também nos leva a ter em conta que o processo de gramatização do português brasileiro já é um modo de distribuir a língua que a diferencia do português europeu, de Portugal. Nesse sentido, é atuar de forma a considerar a maneira pela qual essas línguas podem adquirir outras divisões determinadas pela representação do espaço de enunciação, por sua configuração material, através de outros processos de significação, pois relativamente às definições acima, o espaço de enunciação é o modo de distribuir as línguas que estão em relação.

Qual é o lugar da língua materna para seus falantes, ou o da língua nacional, assim como o da língua oficial, ou ainda o da estrangeira? E esta distribuição é sempre marcada por uma desigualdade politicamente construída. Ou seja, a distribuição dessas línguas para seus falantes constitui uma hierarquia entre elas e atribui um sentido para esta hierarquia. (Idem).

Tomando o ensino de línguas, essa questão se torna consequente e coerente quando consideramos como a Semântica do Acontecimento nos embasa de modo a caracterizar uma especificidade no modo de tratar o sentido e a língua. Essas noções descritas e interpretadas em Guimarães e outros autores que se inscrevem teoricamente nesse campo são diferentes das que se observa em uma gramática, dicionário ou material de ensino de caráter puramente didático, escrito, produzido, compilado para o ensino de estruturas que se valem de frases ou textos produzidos para o ensino de gramática, quando muito de uma gramática contextualizada no texto. Estamos afirmando, com isso, que a teoria engendra conceitos e interpretações que fornecem as bases teórico-metodológicas para a reflexão sobre um funcionamento histórico da língua/linguagem no ensino. Nesse sentido, vale dizer, esta não é uma teoria de ensino, nos moldes do que se apresenta na Linguística Aplicada; ela contribui, no entanto, com o avanço da discussão sobre a língua ao considerar sua divisão e distribuição no ensino. O que está em questão, então, a partir da relação entre a distribuição e divisão de uma língua no espaço de enunciação, é a diferença da Semântica do Acontecimento no modo de observar a(s) língua(s), o que promove uma injunção no modo de tratar os instrumentos linguísticos e a instrumentalização das línguas nos materiais de ensino ${ }^{15}$.

\footnotetext{
${ }^{14}$ Valemo-nos da definição em Orlandi (2005), segundo a qual a língua brasileira (ou brasileiro) é tomada na relação entre a língua imaginária, o português, e a língua fluida, a falada pelos brasileiros.

${ }^{15}$ Vamos tratar dessa questão aqui de modo tácito, não discutindo mais a fundo as divisões que se fazem entre um material didático (um método de ensino reduzido ao livro) e uma designação mais ampla como material de ensino. Compreendemos, contudo, que essa expressão contempla com maior precisão a relação que queremos estabelecer entre um material didático que se utiliza de sequências linguísticas didatizadas, ou seja, só para o ensino ou um material que se utiliza também de textos autênticos. A prática de ensino então é uma prática enunciativa, de tomada de posição, histórica.
} 
Tal prática é fundamental para que os professores, que se inscrevem em determinados lugares sociais, considerem que o funcionamento das línguas se dá sempre em relação, seja em âmbito de sua própria variância ou em suas relações históricas com outras línguas.

A importância de uma reflexão como esta que estamos fazendo, então, está justamente no modo como a teoria embasa as reflexões que fazemos em sala de aula nas diferentes modalidades de ensino de português. E também tem a ver como o nosso processo formativo e com o modo como vamos construindo um trabalho de ensino de línguas que considere essa relação sempre, contínua e histórica entre falantes e línguas. Dessa forma, é preciso considerar que ensinar uma língua é ensinar sua história, seus processos de gramatização - no sentido de que a gramática é "simultaneamente uma técnica pedagógica de aprendizagem das línguas e um meio de descrevê-las" (AUROUX, 2001, p. 36). Retomamos aqui os trabalhos de Guimarães (2005 e 2006), em História das Ideias Linguísticas, que mostram a partir de uma visada histórica, o modo como se constituem os espaços de enunciação para o português, a língua do colonizador português, em relação com as línguas indígenas, espanhola, francesa, holandesa, em diferentes períodos da colonização e depois com as línguas de imigração (italiano, alemão, polonês, etc.) e então com o processo de gramatização do português brasileiro. Ou seja, é necessário considerar esses processos no ensino de uma língua, pois tal prática está diretamente ligada ao seu processo de instrumentalização, que produz naturalizações e opacidades; apagando as divisões da língua; significando a língua do Estado, como se fosse única, homogênea e a língua da escola como a língua de uma gramática, não diferenciando o nome da língua de seu funcionamento e de suas descrições. Assim, é preciso trazer à tona uma discussão sobre o nome da língua a ser ensinada no interior de uma modalidade, pois esta é uma relação entre línguas e falantes que se dá a partir de outra relação enunciativa, que é o modo de representar os aprendentes-locutores, aqueles para quem se (fala) ensina uma língua.

\section{Considerações e alguns encaminhamentos: português para quem?!}

A fim de dar um encaminhamento às questões que trouxemos para reflexão ao longo do texto, tendo em vista as concepções teóricas expostas, a proposta foi mostrar alguns aspectos sobre o modo como a Semântica do Acontecimento pode embasar e determinar nossa atuação como professores de língua.

Quando falamos em apropriação teórica, referimo-nos à assunção desse lugar de docente pesquisador, de crítico, de cientista, mas também de falante dessa língua que está ali, no foco do processo de apropriação pelo aluno. Pensamos no docente que consegue articular os conhecimentos científicos à sua prática de convivência com os alunos-falantes-aprendentes diante de diferentes materiais e textos; um leque de materialidades.

Aproveitamos o ensejo, também, para nos posicionarmos diante de uma conjuntura acadêmico-cientifica que está em constante movimento e que se abre a progressos e retrocessos. É preciso refletir, com efeito, sobre o processo de institucionalização dos saberes e suas relações com os diferentes níveis de formulação e circulação do conhecimento, ou seja, fazer uma ponte entre as escolas de formação básica e média, técnica, as universidades e a sociedade em geral; é preciso reverberar sobre as especificidades dos públicos-alvo, e o modo como essa expressão-conceito é tomada por uma vertente que já é atravessada por determinado modo de considerar o discurso, o conhecimento e o ensino, dentro de uma esfera pragmática, nivelar e, de certo modo, hierarquizante, e possibilitar, dar visibilidade aos diversos modos de 
conceber as práticas científicas e de ensino. Nesse sentido, é necessário que haja leitores capazes de compreender o modo como esse conhecimento é produzido e como ele circula.

Toda nossa exposição considera as divisões da língua bem como as conjunturas de seu ensino, em particular a nossa atuação no ensino de Português no Brasil, em escolas regulares e no ensino de português (brasileiro) para estrangeiros em universidades. A nossa proposta foi a de pensar o modo como o português é tomado como uma língua no ensino para os brasileiros: se ensina português como língua e se ensina em português outras disciplinas, que é distribuído em relação ao inglês ou espanhol, como língua estrangeiras, para os estudantes de escolas públicas ou privadas, ou ensino de português, a língua oficial e uma das línguas nacionais do Brasil, a ser ensinada a estrangeiros, no Brasil ou no exterior. É preciso, por isso, deslocar-se do imaginário do monolinguismo, de que no Brasil se fala só português e que a língua a ser ensinada é desprovida de brasilidade e das relações com outras línguas. É necessário, ainda, abordar o ensino do português como língua oficial e não natural dos brasileiros. Este é ponto de inflexão entre o ensino de português no Brasil para os brasileiros ou o ensino de português como língua estrangeira no Brasil ou no exterior. Isso é o que consideramos uma prática científica, pois não se pode prescindir dessas divisões se queremos trabalhar com embasamentos científicos de todas as ordens. É a esse processo que estamos chamando semântico.

Tomar a Semântica significada na relação com o texto e com a argumentação, da maneira como expusemos, significa que estamos operando sempre com o sentido; estamos sempre lidando com uma materialidade significante, que não está restrita ao capítulo "antonímia, sinonímia, etc." de algum material. Esta forma de tomar o texto enquanto algo exposto às regularidades e às irregularidades próprias da enunciação e que só são apreensíveis no exercício de interlocução/leitura também produz ecos na forma de ensinar uma língua.

Nesse sentido, poderíamos dizer que independente da forma como a semântica aparece, por exemplo, nos materiais didáticos, o trabalho com a linguagem e com a língua implica, inevitavelmente, um trabalho com os sentidos; sempre estamos exercitando, seja nos trabalhos escolares, seja em nossas práticas cotidianas nossos lugares de autores, leitores, sujeitos de sentido.

Não pretendemos, com esse texto, trazer respostas, ou caminhar para uma proposta didática. Pretendemos, sobretudo, fazer uma provocação e um convite a observar nossa língua e suas divisões sob outro aspecto; convite à reverberar sobre as possibilidades com as quais a linguagem e seu funcionamento nos brinda; um convite a observar que os processos de linguagem estão na nossa forma de compreensão do mundo, da nossa sociedade, dos sujeitos que somos e daqueles com os quais convivemos; a relembrar que somos sujeitos de linguagem constituídos nessa relação de identificação com/pela língua que falamos e pela qual somos faladas. Um convite a entender que a produção de sentidos não é engessada e que é fascinante; que não há que possa deslegitimar o nosso lugar de autores quando assumimos esse papel: autores na produção dos textos e autores na interpretação. E todo esse gesto, para nós, é um trabalho semântico; é a semântica na sala de aula, na sala de aula de língua portuguesa (materna, estrangeira, a nossa, a outra língua); na aula que expõe, ensina sobre, permite ser.

\section{REFERÊNCIAS}

AUROUX, S. A revolução tecnológica da gramatização. Trad. Eni Orlandi. Campinas: Editora da UNICAMP, 2001. 
BENVENISTE, É. [1966]. Problemas de Linguística Geral I. - 2. ed. - Campinas, SP: Pontes: Editora da Universidade Estadual de Campinas, 1988.

DUCROT, O. Revista Brasileira De Letras. Os topoï na "teoria da Argumentação na língua”. São Carlos. Universidade Federal de São Carlos. n. 1, 1999.

FERRAREZI JUNIOR, C.; BASSO, R. Semântica, semânticas: uma introdução. São Paulo: Contexto, 2013

FERREIRA, A.C. Um Percurso pela História da Semântica da Enunciação. Web Revista Discursividades. ed. 09, 2012

GUIMARÃES, E. A língua portuguesa no Brasil. Ciência e Cultura. vol.57. no.2 São Paulo. Apr/June. 2005

. Análise de texto: Procedimentos, análises, ensino: Campinas, Editora RG, 2011.

. Argumentação e argumentatividade. Revista do Programa de PósGraduação em Letras da Universidade de Passo Fundo - v. 9 - n. 2 - p. 271-283 jul./dez. 2013

.. Espaço de enunciação e política de línguas no Brasil. In: SANTOS, J.e Oliveira, S. E. (Orgs). Mosaicos de Linguagem. Guarapuava, PR: Cellip - Campinas, SP: Pontes, 2006. p. 11-27.

. Os Limites do Sentido. 4. ed. Campinas: Pontes, 2010

Semântica do Acontecimento. Campinas: Pontes, 2002.

ORLANDI, E. P. A Língua brasileira. Ciência e Cultura On-line version ISSN 2317 6660. Cienc. Cult. vol.57 no.2 São Paulo Apr./June 2005.

. Terra à Vista. Discurso do confronto: velho e novo mundo. $2^{\mathrm{a}}$ ed. Campinas-SP: Editora da Unicamp, 2008

STAHLHAUER, A. S. M. Relação de Línguas no espaço enunciativo da propaganda: a argumentação, a enunciação e o político. Dissertação de Mestrado. Universidade Federal de São Carlos. 2010

. A Brasilianistik como um campo de estudos alemão sobre o Brasil e sua língua. Fragmentum n. 52. Jul./Dez. 2018. Santa Maria: Editora Programa de PósGraduação em Letras, UFSM. ISSN 2179-2194 (online); 1519-9894 (impresso), 2019.

Recebido em: novembro de 2019.

Aprovado em: dezembro de 2019.

\section{Como citar este trabalho:}

STAHLHAUER, A. S. M., REIS, C. F. Texto, enunciação e as práticas (políticas) de ensino de línguas: contribuições da Semântica do Acontecimento para pensar os sentidos no ensino da língua portuguesa. Traços de Linguagem. V.3, n.2, p. 85-96, 2019. 